\title{
PERAN KADER KESEHATAN DALAM MENSUKSESKAN PROGRAM KELAS IBU HAMIL DI WILAYAH KERJA PUSKESMAS KEDUNGMUNDU TAHUN 2016
}

\author{
Siti Nur Umariyah Febriyanti ${ }^{1}$, Evi Yulianti ${ }^{2}$ \\ ${ }^{12}$ Prodi D IV Kebidanan Stikes Karya Husada Semarang \\ E-mail : snu.febriyanti@gmail.com
}

\begin{abstract}
ABSTRAK
Latar Belakang : Kelas ibu hamil adalah sarana belajar bersama tentang kesehatan bagi ibu hamil difasilitasi oleh bidan atau tenaga kesehatan. Hasil survey awal kepada bidan koordinator ruang KIA, kegiatan kelas ibu hamil di wilayah kerja Puskesmas Kedungmundu belum berjalan dengan maksimal, data dari poli KIA tahun 2015 tercatat 2449 ibu hamil, yang mengikuti kegiatan kelas ibu hamil sebanyak 70 ibu atau (3,498\%). Keberhasilan program kelas ibu hamil sangat bergantung pada dukungan peran serta masyarakat atau kader kesehatan. Tujuan : Mengeksplorasi peran kader kesehatan dalam mensukseskan program kelas ibu hamil di wilayah kerja Puskesmas Kedungmundu. Metode Penelitian : Penelitian ini dengan metode kualitatif, pendekatan deskriptif fenomenologi, teknik pengumpulan data wawancara mendalam, partisipan 3 kader kesehatan, pada tanggal 21-28 April 2016. Hasil : Peran kader kesehatan dalam persiapan kelas ibu hamil sudah baik, meliputi koordinasi dengan fasilitator yaitu bidan, melakukan penjaringan peserta, memotifasi ibu-ibu hamil untuk hadir dalam kelas ibu hamil, serta mempersiapkan tempat dan alat. Peran kader kesehatan dalam pelaksanaan kelas ibu hamil sudah baik, yaitu mendampingi ibu hamil selama kegiatan, melakukan pencatatan dalam daftar hadir, evaluasi setelah kegiatan, dan melaporkan kepada fasilitator yaitu bidan. Kendala dan hambatan pelaksanaan kelas ibu hamil adalah ibu hamil tidak bisa datang sesuai jadwal yang sudah ditentukan, karena sebagian ibu hamil bekerja. Penyelesaian kendala atau hambatannya yaitu me-reschedule jadwal kegiatan, dengan berkoordinasi antara bidan pelaksana, kader, dan gasurkes. Saran : Kader kesehatan hendaknya melakukan pendekatan kepada ibu-bu hamil di wilayahnya, guna mendiskusikan kapan waktu bisa mengikuti kegiatan kelas ibu hamil, untuk selanjutnya dikoordinasikan kepada tim fasilitator.
\end{abstract}

Kata Kunci: Peran kader kesehatan; kelas ibu hamil

\section{HEALTH CADRE ROLE IN THE SUCCESS OF CLASS PROGRAM OF PREGNANT WOMEN IN THE WORKING AREA OF PRIMER HEALTH CARE KEDUNGMUNDU IN 2016}

\begin{abstract}
Background : Class of pregnant women is a means to learn together about the health of pregnant womens is facilitated by midwives or health professionals. The result of the initial survey with the coordinator of midwives in Maternal and Child Health (MCH) room, the class of pregnant women in the work area of the Primary Healt Care (PHC) in Kedungmundu has not gone up. The data from poly MCH on 2015 recorded 2449 pregnant women, who participated in class is 70 pregnant women or $(3.498 \%)$. The success of this program depends on the support of the cadres. Purpose : The purpose of this research was to explore the role of. For the success of the program's in PHC Kedungmundu. Method of The Research : This research a qualitative method, fenomenologi descriptive, the techniques for collecting data in depth interview,s participant 3 cadres on, 21-28 April 2016. Result : The role of health cadres in preparation for the class of pregrant women has been good, such as coordination with the midwife, collecting the respondents, motivating the pregnant womens to attend the class, and preparing place and tools. The role of health cadres in the class of pregnant has been good such as assisting the pregnant women during activites. Keep records on the attendance list, evaluating after activities, and reported to the midwife, the obstacles and barriers in the class of pregnant women were pregnant women can not come accordance with a fixed schedule, because most pregnant women who are working. the completion of obstacles or barriers, is re-schedule and coordinating between midwifery, carders and gasurkes. Suggestion : Health cadres should approach with pregnant womens in the region to discuss the time when the pregnant women can participant in class, and then cordineting with the facilitator team.
\end{abstract}

Key words: The Role of Health Cadre; Class Of Pregnant Women 


\section{Pendahuluan}

Kelas Ibu Hamil adalah kelompok belajar ibu-ibu hamil dengan umur kehamilan antara 4 minggu s/d 36 minggu (menjelang persalinan) dengan jumlah peserta maksimal 10 orang. Tujuan diadakannya program kelas ibu hamil adalah sebagai sarana untuk belajar bersama tentang kesehatan bagi ibu hamil, dalam bentuk tatap muka dalam kelompok yang bertujuan meningkatkan pengetahuan dan keterampilan ibu-ibu mengenai kehamilan, perawatan kehamilan, persalinan, perawatan nifas, perawatan bayi baru lahir, penyakit menular, hingga mitos yang berkembang di masyarakat. Dengan begitu, diharapkan adanya program kelas ibu hamil ini dapat membantu meningkatkan kesehatan ibu dan anak, mewujudkan keluarga yang sehat dan sejahtera, serta menekan (AKI) Angka Kematian Ibu (DepKes RI, 2011).

Keberhasilan program kelas ibu hamil juga sangat bergantung pada dukungan dan peran serta masyarakat di wilayah kerja yang mengadakan program kelas ibu hamil tersebut. Salah satu upaya pemberdayaan masyarakat dari pemerintah demi tercapainya programprogram kesehatan yaitu dengan mengikutsertakan anggota masyarakat atau kader yang bersedia secara suka rela terlibat dalam masalah-masalah kesehatan. Kader merupakan orang terdekat yang berada ditengah masyarakat, yang diharapkan dapat memegang pekerjaan penting khususnya setiap permasalahan yang berkaitan dengan kesehatan. Dengan demikian, upaya kesehatan bukan hanya dari pemerintah saja, peran serta masyarakat/kader merupakan unsur mutlak dalam kegiatan upaya kesehatan kemandirian masyarakat (Yulifah R, 2009).

Survey awal yang telah dilakukan peneliti di Puskesmas Kedungmundu, kepada Bidan koordinator ruangan KIA mengenai fenomena atau masalah kesehatan yang terjadi di masyarakat saat ini, menunjukkan bahwa program kegiatan kelas ibu hamil di wilayah kerja Puskesmas Kedungmundu belum berjalan dengan baik. Pada awalnya pelaksanaan kegiatan kelas ibu hamil di wilayah kerja Puskesmas Kedungmundu normatifnya dilakukan satu bulan sekali, namun kenyataan/masalah yang terjadi di lapangan, penjaringan untuk peserta kegiatan kelas ibu hamil oleh kader kesehatan belum bisa maksimal, masih banyak ibu hamil yang tidak aktif kehadirannya dalam kegiatan kelas ibu hamil. Data dari Poli KIA Puskesmas Kedungmundu tahun 2015, tercatat jumlah ibu hamil di wilayah kerja Puskesmas Kedungmundu adalah $2449 \mathrm{ibu}$, namun yang mengikuti kegiatan kelas ibu hamil hanya sebanyak 70 ibu hamil saja atau (3,498\%). Akibatnya kegiatan kelas ibu hamil tidak berjalan dengan maksimal dan hanya dilakukan tiga kali dalam satu tahun. 
Kader yang telah dibekali keterampilan kesehatan oleh sarana kesehatan atau Puskesmas setempat selanjutnya diharapkan mampu menggerakkan masyarakat khususnya ibu hamil untuk lebih sadar dalam kegiatan program-program kesehatan, khususnya program kegiatan kelas ibu hamil, karena selanjutnya kader kesehatan inilah yang akan menjadi motor penggerak, pengelola berjalan atau tidaknya, sukses atau tidaknya program kelas ibu hamil ini. Berdasarkan latar belakang di atas peneliti tertarik melakukan penelitian tentang " Peran Kader Kesehatan Dalam Mensukseskan Program Kelas Ibu Hamil Di Wilayah Kerja Puskesmas Kedungmundu Tahun 2016".

\section{Tinjauan Teoritis}

\section{A. Peran Kader}

Peran adalah serangkaian perilaku yang diharapkan sesuai dengan posisi sosial yang diberikan sehingga pada struktur peran bisa bersifat formal atau informal (Tantut $S$, 2012). Kader kesehatan adalah warga masyarakat yang terpilih dan diberi bekal keterampilan kesehatan melalui pelatihan oleh sarana pelayanan kesehatan atau puskesmas setempat. Kader kesehatan inilah yang selanjutnya akan menjadi motor penggerak atau pengelola dari upaya kesehatan primer. Kader diharapkan mampu menggerakkan masyarakat untuk melaporkan kegiatan yang bersifat swadaya dalam rangka peningkatan status kesehatan. Kegiatan-kegiatan yang dilakukan meliputi kegiatan yang sifatnya promotif, preventif, kuratif maupun rehabilitative (Notoatmodjo, 2010).

Yulifah R (2009), peran kader kesehatan yaitu kader kesehatan mempunyai peran besar dalam upaya meningkatkan kemampuan masyarakat menolong dirinya untuk mencapai derajat kesehatan yang optimal. Kader juga berperan dalam pembinaan masyarakat di bidang kesehatan melalui kegiatan yang dilakukan di posyandu. Selain dalam kegiatan posyandu, kader juga mempunyai peran diluar kegiatan posyandu, yaitu sebagai berikut:

1) Merencanakan kegiatan, antara lain merencanakan dan melaksanakan survei mawas diri, membahas hasil survei, menentukan masalah dan kebutuhan kesehatan masyarakat desa, menentukan kegiatan penanggulangan masalah kesehatan bersama masyarakat, serta membahas pembagian tugas menurut jadwal kerja.

2) Melakukan komunikasi, memberikan informasi, dan motivasi tatap muka (kunjungan) dengan menggunakan alat peraga, serta melakukan demonstrasi (memberikan contoh). 
3) Menggerakkan masyarakat, mendorong masyarakat untuk bergotong royong, memberikan informasi serta mengadakan kesepakatan kegiatan yang akan dilakukan.

4) Memberikan pelayanan, yaitu membagi obat, membantu mengumpulkan bahan pemeriksaan, mengawasi pendatang di desanya dan melaporkannya, memberikan pertolongan pemantauan penyakit, serta memberikan pertolongan pada kecelakaan.

5) Melakukan pencatatan seperti berikut ini:

a) Keluarga berrencana (KB) atau jumlah pasangan usia subur, jumlah peserta $\mathrm{KB}$ aktif.

b) Kesehatan ibu dan anak (KIA), jumlah ibu hamil, vitamin A yang dibagikan.

c) Imunisasi, seperti jumlah imunisasi tetanus toksoid (TT) ibu hamil dan jumlah bayi atau balita yang diimunisasikan.

d) Gizi, seperti jumlah bayi yang mempunyai KMS, balita yang di timbang dan yang naik timbangannya.

e) Diare, seperti jumlah oralit yang dibagikan, penderita yang ditemukan dan dirujuk.

6) Melakukan pembinaan mengenai lama program keterpaduan KB-kesehatan dan upaya kesehatan lainnya.

7) Melakukan kunjungan rumah kepada masyarakat terutama keluarga binaan.

8) Melakukan pertemuan kelompok.

\section{B. Kelas Ibu Hamil}

Kelas ibu hamil merupakan sarana untuk belajar bersama tentang kesehatan bagi ibu hamil, dalam bentuk tatap muka dalam kelompok yang bertujuan untuk meningkatkan pengetahuan dan keterampilan ibu-ibu mengenai kehamilan, perawatan kehamilan, persalinan, perawatan nifas, perawatan bayi baru lahir, mitos, penyakit menular, dan akte kelahiran (Depkes RI, 2011). Menurut Depkes RI (2011), beberapa tahapan yang dilakukan untuk melaksanakan kelas ibu hamil antara lain:

1) Pelatihan bagi pelatih (TOT)

Pelatihan bagi pelatih dipersiapkan untuk melatih bagi para fasilitator di tempat pelaksanaan kelas ibu hamil, baik di tingkat kabupaten, Kecamatan sampai ke desa.Peserta TOT adalah bidan atau petugas kesehatan yang sudah mengikuti sosialisasi tentang Buku KIA dan mengikuti pelatihan fasilitator. Kegiatan TOT bertujuan untuk mencetak para fasilitator dan selanjutnya fasilitator akan mampu melaksanakan serta mengembangkan pelaksanaan kelas ibu hamil. 
2) Pelatihan bagi fasilitator

Pelatihan fasilitator dipersiapkan untuk melaksanakan kelas ibu hamil.Fasilitator kelas ibu hamil adalah bidan atau petugas kesehatan yang telah mendapatkan pelatihan fasilitator kelas ibu hamil atau on the job training.Bagi bidan atau petugas kesehatan ini, boleh melaksanakan pengembangan kelas ibu hamil di wilayah kerjanya. Untuk mencapai hasil yang optimal dalam memfasilitasi kelas ibu hamil, fasilitator hendaknya menguasai materi yang akan disajikan baik materi medis maupun non medis. Beberapa materi non medis berikut akan membantu Kemampuan fasilitator dalam pelaksanaan kelas ibu hamil diantaranya : Komunikasi interaktif, Presentasi yang baik, Menciptakan suasana yang kondusif.

3) Sosialisasi kelas ibu hamil pada tokoh agama, tokoh masyarakat, dan stakeholder Sosialisasi ini sangat penting.Melalui kegiatan sosialisasi ini diharapkan semua unsur masyarakat dapat memberikan respon dan dukungan sehingga kelas ibu hamil dapat dikembangkan dan berjalan sesuai dengan yang diharapkan.

Materi sosialisasi antara lain : buku KIA, apa itu kelas ibu hamil, tujuan pelaksanaan kelas ibu hamil, manfaat kelas ibu hamil, peran tokoh agama, tokoh masyarakat dan stakeholder dalam mendukung pelaksanaan kelas ibu hamil.

4) Persiapan pelaksanaan kelas ibu hamil

Hal-hal yang perlu dipersiapkan sebelum pelaksanaan kelas ibu hamil :

a) Melakukan identifikasi/mendaftar semua ibu hamil yang ada di wilayah kerja. Ini dimaksudkan untuk mengetahui berapa jumlah ibu hamil dan umur kehamilannya sehingga dapat menentukan jumlah peserta setiap kelas ibu hamil dan berapa kelas yang akan dikembangkan dalam kurun waktu tertentu misalnya, selama satu tahun.

b) Mempersiapkan tempat dan sarana pelaksanaan kelas ibu hamil, misalnya tempat di Puskesmas atau Polindes, Kantor Desa/Balai Pertemuan, Posyandu atau di rumah salah seorang warga masyarakat. Sarana belajar menggunakan, tikar/karpet, bantal dan lain-lain jika tersedia.

c) Mempersiapkan materi, alat bantu penyuluhan dan jadwal pelaksanaan kelas ibu hamil serta mempelajari materi yang akan disampaikan.

d) Persiapan peserta kelas ibu hamil, mengundang ibu hamil umur kehamilan antara 4 sampai 36 minggu.

e) Siapkan tim pelaksana kelas ibu hamil yaitu siapa saja fasilitatornya dan nara sumber jika diperlukan. 
5) Pelaksanaan kelas ibu hamil

Pelaksanaan pertemuan kelas ibu hamil dilakukan sesuai dengan kesepakatan antara tim fasilitator yaitu bidan/petugas kesehatan dengan peserta ibu-ibu hamil, dengan tahapan pelaksanaan.

6) Monitoring, evaluasi dan pelaporan

a) Monitoring

Monitoring di tingkat Provinsi dan Kabupaten/Kota dilakukan minimal setiap 3 (tiga) bulan sekali. Hal-hal yang perlu dimonitor :Peserta (keadaan dan minat peserta, kehadiran peserta, keaktifan bertanya). Sarana prasarana (tempat, fasilitas belajar).Fasilitator (persiapan, penyampaian materi, penggunaan alat bantu,membangun suasana belajar aktif). Waktu (mulai tepat waktu, efektif).

b) Evaluasi

Evaluasi dilakukan untuk melihat keluaran dan dampak baik positif maupun negatif pelaksanaan kelas ibu hamil berdasarkan indikator. Dari hasil evaluasi tersebut bisa dijadikan sebagai bahan pembelajaran guna melakukan perbaikan dan pengembangan kelas ibu hamil berikutnya. Evaluasi oleh pelaksana (Bidan/koordinator bidan) dilakukan pada setiap selesai pertemuan kelas ibu.

c) Pelaporan

Pelaporan disusun pada setiap selesai melaksanakan kelas ibu hamil. Isi laporan minimal memuat tentang : waktu pelaksanaan, jumlah peserta, proses pertemuan, masalah dan hasil capaian pelaksanaan, hasil evaluasi. Pelaporan dilakukan secara berkala dan berjenjang dari bidan pelaksana kelas ibu hamil ke Puskesmas Dinas Kesehatan Kabupaten - Dinas Kesehatan Provinsi - Kementerian Kesehatan.Pelaporan oleh bidan/pelaksana dilakukan setiap selesai pertemuan atau setiap angkatan pelaksanaan kelas ibu hamil, Kabupaten dan Provinsi palaporan disusun setiap 3 (tiga) bulan sekali dan laporan tahunan.

\section{Metode Penelitian}

Penelitian ini menggunakan metode kualitatif, dengan pendekatan deskriptif fenomenologi, teknik pengumpulan data wawancara mendalam, partisipan dalam penelitian adalah kader kesehatan di wilayah kerja Puskesmas Kedungmundu, dengan triangulasi sumber bidan pelaksana kelas ibu hamil dan ibu hamil yang pernah mengikuti kelas ibu hamil. Penilitian ini dilaksanakan pada bulan April 2016. 


\section{Hasil Penelitian}

1. Pengetahuan kader tentang program kelas ibu hamil

Berdasarkan hasil penelitian semua partisipan mengatakan bahwa partisipan mengetahui tentang kelas ibu hamil, yaitu suatu kegiatan belajar bersama untuk ibu-ibu hamil yang didalamnya terdapat kegiatan seperti penyuluhan mengenai kesehatan bagi ibu hamil.

2. Ada atau tidak kegiatan kelas ibu hamil, dan berjalan dengan rutin atau tidak Berdasarkan hasil penelitian semua partisipan mengatakan bahwa di wilayahnya ada kegiatan kelas ibu hamil, tetapi belum berjalan dengan rutin. Partisipan ke tiga juga nenambahkan bahwa pelaksanaan kelas ibu hamil diwilayahnya bergabung di puskesmas.

3. Koordinasi kader dengan bidan pelaksana/pihak puskesmas dalam persiapan kelas ibu hamil

Berdasarkan hasil penelitian semua partisipan mengatakan bahwa selalu ada koordinasi dengan bidan puskesmas sebelum persiapan pelaksanaan kelas ibu hamil.

4. Petugas yang bertanggung jawab, dan petugas yang terlibat dalam pelaksanaan kelas ibu hamil

Berdasarkan hasil penelitian menunjukkan bahwa semua partisipan menerangkan yang bertanggung jawab dalam pelaksanaan kelas ibu hamil adalah bidan dan yang terlibat dalam pelaksanaan kelas ibu hamil adalah kader, kader terlibat sejauh dalam pendataan ibu hamil di wilayahnya untuk persiapan peserta, persiapan tempat dan alat, serta terlibat dalam pencatatan absensi untuk pelaporan kepada bidan pelaksana setelah kegiatan. Namun partisipan pertama juga menambahkan bahwa yang bertanggung jawab sepenuhnya tetap dari bidan Puskesmas.

5. Peran kader kesehatan dalam persiapan kelas ibu hamil

Berdasarkan hasil penelitian menunjukkan bahwa semua partisipan mengatakan dalam persiapan kelas ibu hamil kader berperan dalam hal mempersiapkan tempat dan alat, serta penjaringan peserta kegiatan yaitu ibu hamil di wilayah tempat tinggalnya.

6. Peran kader kesehatan dalam pelaksanaan kelas ibu hamil

Berdasarkan hasil penelitian menunjukkan bahwa dua partisipan yaitu partisipan pertama dan partisipan ke tiga menjelaskan tugasnya dalam pelaksanaan kelas ibu hamil selama ini sebatas melakukan pendampingan kepada peserta kelas ibu hamil.

7. Petugas yang bertugas melakukan pencatatan, evaluasi dan pelaporan sewaktu kegiatan Berdasarkan hasil penelitian menunjukkan bahwa, semua partisipan menerangkan selama ini petugas yang melakukan proses pencatatan sampai evaluasi adalah kader kesehatan. 
Pencatatan dalam bentuk daftar hadir peserta, evaluasi kegiatan yang dilakukan, dan melaporkan kepada fasilitator setelah kegiatan kelas ibu hamil dilakukan.Namun partisipan ke dua juga menambahkan bahwa dalam proses pencatatan sampai dengan evaluasi kader melakukan bersama atau dibantu oleh bidan.

8. Kendala dan hambatan dalam pelaksanaan kelas ibu hamil

Berdasarkan hasil penelitian menunjukkan bahwa dua partisipan yaitu partisipan pertama dan partisipan ke tiga mengatakan ada kendala dan hambatan dalam pelaksanaan kelas ibu hamil selama ini, kendalanya yaitu ibu hamil yang tidak bisa datang pada kegiatan kelas ibu hamil sesuai jadwal yang sudah ditentukan dikarenakan ibu hamil yang bekerja. Dan partisipan ke dua menerangkan selain ibu hamil yang tidak hadir dalam pelaksanaan ada juga ibu hamil yang terkendala transportasi karena jarak dengan puskesmas jauh.

9. Proses penyelesaian kendala atau hambatan pada saat pelaksanaan kegiatan kelas ibu hamil

Berdasarkan hasil penelitian menunjukkan bahwa dua partisipan yaitu partisipan pertama dan ke dua menjelaskan untuk penyelesaian kendala dan hambatan selama ini biasanya dibuat jadwal ulang, mencari waktu yang tepat sesuai peserta ibu hamilnya bisanya kapan.

\section{Pembahasan}

Pengetahuan kader tentang program kelas ibu hamil didapat dari penyuluhan bidan kepada kader tentang program kelas ibu hamil. Informasi terkait program kelas ibu hamil disampaikan bidan saat pertemuan kader, diharapkan dengan informasi tersebut kader memahami tentang program kelas ibu hamil dan mengetahui manfaatnya sehingga bisa mengajak ibu hamil untuk selalu rutin berangkat di kelas ibu hamil. Kegiatan kelas ibu hamil di wilayah Puskesmas Kedungmundu sudah ada tetapi belum berjalan dengan rutin dan pelaksanaan kelas ibu hamil digabungkan dari beberapa kelurahan dan dilaksanakan di puskesmas. Kegiatan kelas ibu hamil bisa berjalan rutin karena beberapa faktor antara lain keaktifan ibu hamil, kader dan tenaga kesehatan. Biaya kelas ibu hamil menggunakan dana BOK Puskesmas dan tidak rutin bisa diberikan sehingga harus swadana, hal tersebut juga menjadi faktor untuk bisa dilakukan kelas ibu hamil.

Kader selalu berkoordinasi dengan bidan puskesmas sebelum persiapan pelaksanaan kelas ibu hamil. Hal tersebut menunjukkan bahwa komunikasi kader dengan tenaga kesehatan sangat baik. Dengan komunikasi yang terjalin baik diharapkan persiapan kelas ibu hamil benar-benar matang dan bisa berjalan dengan lancar. Penanggung jawab pelaksanaan kelas 
ibu hamil adalah bidan Puskesmas Kedungmundu dengan melibatkan kader, kader melakukan pendataan ibu hamil di wilayahnya untuk persiapan peserta, persiapan tempat dan alat, serta terlibat dalam pencatatan absensi untuk pelaporan kepada bidan pelaksana setelah kegiatan. Baik bidan kader berkoordinasi dengan baik.

Kader melakukan persiapan kelas ibu hamil dengan mempersiapkan tempat dan alat, serta penjaringan peserta kegiatan yaitu ibu hamil di wilayah tempat tinggalnya. Kader secara aktif mengajak ibu hamil untuk datang di kelas ibu hamil. Kader juga melakukan pendampingan kepada peserta kelas ibu hamil saat pelaksanaan kelas ibu hamil, kegiatan penyuluhan dilakukan oleh bidan. Kader juga berperan sebagai fasilitator yang mendampingi bidan dalam pelaksanaan kegiatan kelas ibu hamil. Kader kesehatan mempunyai peran besar dalam upaya meningkatkan kemampuan masyarakat menolong dirinya untuk mencapai derajat kesehatan yang optimal (Yulifah R, 2009).

Petugas yang melakukan proses pencatatan sampai evaluasi adalah kader kesehatan. Pencatatan dalam bentuk daftar hadir peserta, evaluasi kegiatan yang dilakukan, dan melaporkan kepada bidan setelah kegiatan kelas ibu hamil dilakukan. Kader dan bidan berkoordinasi dalam pencatatan, evaluasi dan pelaporan kegiatan kelas ibu hamil.

Kendala dalam pelaksanaan kelas ibu hamil adalah ibu hamil tidak semuanya bisa datang sesuai jadwal karena ibu hamil yang bekerja dan terkendala transportasi karena jarak dengan puskesmas jauh. Beberapa kendala tersebut bisa diatasi dengan dilakukannya kelas ibu hamil di tiap kelurahan, tapi hal tersebut juga tidak memungkinkan untuk dilakukan karena alasan biaya. Penyelesaian yang lain adalah dibuat jadwal ulang pelaksanaan kelas ibu hamil dengan mencari waktu yang tepat sesuai kemauan ibu hamilnya.

\section{Kesimpulan}

1. Peran kader kesehatan dalam persiapan kelas ibu hamil sudah cukup baik, mulai dari koordinasi dengan tim fasilitator, melakukan penjaringan peserta sekaligus memotifasi ibu-ibu hamil untuk hadir dalam kegiatan kelas ibu hamil, serta mempersiapkan tempat dan alat.

2. Peran kader kesehatan dalam pelaksanaan kelas ibu hamil sudah cukup baik, yaitu mendampingi ibu hamil selama kegiatan, melakukan pencatatan dalam bentuk daftar hadir, evaluasi kegiatan yang dilakukan, dan melaporkan kepada fasilitator.

3. Kendala dan hambatan dalam pelaksanaan kelas ibu hamil yaitu ibu hamil yang tidak bisa datang pada kegiatan kelas ibu hamil sesuai jadwal yang sudah ditentukan, karena 
sebagian ibu hamil bekerja. Penyelesaian kendala atau hambatannya yaitu me-reschedule jadwal kegiatan, dengan berkoordinasi antara bidan pelaksana, kader, dan gasurkes.

\section{Saran}

1. Bagi Kader Kesehatan

Diharapkan bagi kader kesehatan hendaknya melakukan pendekatan kepada ibu hamil di wilayahnya, guna mendiskusikan kapan waktu ibu-ibu hamil yang bisa mengikuti kegiatan kelas ibu hamil, untuk selanjutnya dikoordinasikan kepada tim fasilitator/bidan. Kader hendaknya lebih aktif dalam setiap pertemuan atau pelatihan kader untuk bisa lebih meningkatkan pengetahuan tentang kelas ibu hamil.

2. Bagi Puskesmas Kedungmundu

Diharapkan agar petugas kesehatan khususnya bidan yang memegang program kerja kelas ibu hamil hendaknya terus melakukan promosi berupa penyuluhan dengan cara menggunakan lembar balik atau leaflet tentang kegiatan kelas ibu hamil, me-reschedule jadwal kegiatan kelas ibu hamil seperti contohnya kegiatan kelas ibu hamil dilakukan diluar jam kerja atau di hari libur.

3. Bagi Peneliti Selanjutnya.

Bagi peneliti selanjutnya hendaknya dapat menambah lebih banyak sumber bacaan mengenai peran kader untuk melakukan penelitian yang sama dan lebih menggali secara mendalam dengan desain variabel yang berbeda.

\section{Daftar Referensi}

Depkes RI. 2011. Selamat Datang di Kelas Ibu Hamil.Jakarta: Direktorat Jenderal Bina Kesehatan Masyarakat.

.2011. Pedoman Pelaksanaan Kelas Ibu Hamil. Jakarta: Direktorat Bina Kesehatan Masyarakat Departemen Kesehatan Indonesia.

Notoatmodjo, Soekidjo.2010.Metodologi Penelitian Kesehatan. PenerbitRineka Cipta: Jakarta.

Tantut, Susanto. 2012. Buku Ajar Keperawatan Keluarga. Penerbit Trans Info Media: Jakarta. Yulifah Rita. 2009. Asuhan Kebidanan Komunitas. Penerbit Salemba Medika: Jakarta. 